\title{
Chemotherapeutic Effect of Withaferin A in Human Oral Cancer Cells
}

\author{
In-Hyoung Yang*, Lee-Han Kim*, Ji-Ae Shin, Sung-Dae Cho\# \\ Department of Oral Pathology, School of Dentistry, Institute of Biodegradable Material, Institute of Oral \\ Bioscience, Chonbuk National University, Jeonju, Republic of Korea \\ Email: "
}

Received 17 July 2015; accepted 7 August 2015; published 10 August 2015

Copyright (C) 2015 by authors and Scientific Research Publishing Inc.

This work is licensed under the Creative Commons Attribution International License (CC BY).

http://creativecommons.org/licenses/by/4.0/

(c) (i) Open Access

\begin{abstract}
Withaferin A (WA) is a bioactive compound derived from a medicinal plant Withania somnifera and has potential therapeutic effects against various types of cancers. The purpose of this study is to investigate an apoptotic effect of WA and identify its molecular target in HSC-3 and HSC-4 human oral cancer cell lines using Trypan blue exclusion assay, DAPI staining and western blotting. WA inhibited cell viability and induced apoptosis in a concentration- or time-dependent manner, as evidenced by induction of nuclear condensation and fragmentation, activation of caspase 3 and poly (ADP-ribose) polymerase (PARP) cleavage. WA-induced apoptosis was partly diminished by Z-VAD, a pancaspase inhibitor. WA also increased Bim and Bax protein in HSC-3 and HSC-4 cells, respectively. These results suggest that WA may be a potential chemotherapeutic drug candidate against human oral cancer.
\end{abstract}

\section{Keywords}

Oral Cancer, Withaferin A, Apoptosis, Bim, Bax

\section{Introduction}

Anticancer agents including cisplatin and pingyangmycin have been generally used in head and neck and tongue cancer treatment by suppressing tumor size and inhibiting metastasis [1] [2]. However, it has been reported to have toxicity, side effect and resistance to apoptosis in ovarian and tongue cancer [2] [3]. The failure of current therapies in adrenocortical carcinoma has been reported to be correlated with cytotoxic drugs containing cisplatin, etoposide, mitotane and doxorubicin [4]. For this reason, novel agents with low toxicity are necessary to be

*Both authors are equally contributed to this work.

${ }^{\#}$ Corresponding author. 
developed for the treatment of various cancers including oral cancer.

Natural compounds derived from plant sources have steadily been known as invaluable source of therapeutic agents [5]. They were also used as traditional medicines for the treatment of various cancers because of their potential anti-cancer effects [6]-[8]. Withania somnifera is a plant with bioactive compounds, which has been known as winter cherry or Indian ginseng [9]. WA, derived from Withania somnifera, has therapeutic effects, such as anti-inflammatory, anti-angiogenesis and anti-cancer effects in various cancers [9]-[11]. It has been reported that WA suppressed cell growth and induced apoptosis in breast cancer cells in vitro and in vivo [12]. WA also induced apoptosis in human melanoma cells [13]. Thus, WA has a great possibility to become an effective cancer therapy.

$\mathrm{Bcl}-2$ family proteins have been characterized as cell survival factors (Bcl-2, Bcl- $\mathrm{X}_{\mathrm{L}}, \mathrm{Mcl}-1$ and so on) and pro-apoptotic factors (Bak, Bax, Bim, Bid and so on), which can regulate mitochondria-dependent apoptosis [14]. These proteins include at least one of four BCL-2 homology domains, BH1 to BH4 [15]. BH3-only proteins, Bim and Bid act upstream of Bax and Bak with BH1-BH3 domains to induce apoptosis [16]. It has been demonstrated that Bim activates the apoptotic proteins Bax and Bak, leading to cytosolic release of cytochrome c from mitochondria and induce apoptosis [17]. Recently, WA-induced apoptosis has been studied in various cancer cell lines, such as breast [18], prostate [19], pancreatic [20], ovarian [21], lung [22], head and neck cancer cell lines [23]. However, the detailed molecular target behind the apoptosis of human oral cancer cells is not clear yet. Therefore, it is valuable to investigate the molecular target of WA-induced apoptosis in human oral cancer cells. In this study, our group investigated the efficacy of WA through the regulation of Bcl-2 family proteins in human oral cancer cells.

\section{Materials and Methods}

\subsection{Cell Culture and Chemical Treatment}

HSC-3 and HSC-4 cells were provided by Hokkaido University (Hokkaido, Japan). Cells were cultured in DMEM supplemented with $10 \% \mathrm{FBS}$ and antibiotics at $37^{\circ} \mathrm{C}$ in $5 \% \mathrm{CO}_{2}$ incubator. All experiments were prepared in cells cultured at 50\% - 60\% confluence. Withaferin A (Sigma, St. Louis, Mo, USA) was dissolved in $0.1 \%$ DMSO (vehicle control) and stored at $-20^{\circ} \mathrm{C}$. Final concentration of DMSO did not exceed $0.1 \%$. Z-VAD (Minneapolis, Minnesota, USA) was treated as a pan-caspase inhibitor into cell lines.

\subsection{Trypan Blue Exclusion Assay}

The growth inhibitory effect of WA was determined with trypan blue solution (Gibco, Paisley, UK). Cells were stained with trypan blue (0.4\%), and then viable cells were counted using a hemocytometer.

\subsection{4'-6-Diamidino-2-Phenylindole (DAPI) Staining}

To detect nuclear morphological changes of apoptotic cells, cells were stained with DAPI solution (SigmaAldrich, Louis, MO, USA). Briefly, cells were fixed in 100\% methanol at RT for 10 min, deposited on slides, and stained with DAPI solution $(2 \mu \mathrm{g} / \mathrm{ml})$. The morphological changes of apoptotic cells were observed under a fluorescence microscopy.

\subsection{Western Blot Analysis}

Whole-cell lysates were prepared with lysis buffer and protein concentration in each sample was measured using a DC Protein Assay Kit (BIO-RAD Laboratories, Madison, WI, USA). After normalization, equal amounts of protein were separated by SDS-PAGE and then transferred to Immun-Blot ${ }^{\mathrm{TM}}$ PVDF membranes. The membranes were blocked with 5\% skim milk in TBST at RT for $2 \mathrm{hr}$, and incubated with primary antibodies and corresponding HRP-conjugated secondary antibodies. Antibodies against cleaved PARP, cleaved caspse-3, Bax and Bim were purchased from Cell Signaling Technology, Inc., (Charlottesville, VA, USA). Actin antibody was obtained from Santa Cruz Biotechnology, Inc., (Santa Cruz, CA, USA). The immunoreactive bands were visualized by ImageQuant ${ }^{\mathrm{TM}}$ LAS 500 (GE Healthcare Life Sciences, Piscataway, NJ, USA).

\subsection{Statistical Analysis}

Student's $t$-test was used to determine the significance of differences between the control and treatment groups; 
values of $p<0.05$ were considered significant.

\section{Results}

\subsection{WA Reduces the Viability in HSC-3 and HSC-4 Cells}

To explore the potential anti-cancer effects of WA in human oral cancer cells, we examined the effects of WA by cell counting after the treatment with DMSO or various concentrations for $24 \mathrm{hr}$ as well as certain concentration ( $1 \mu \mathrm{M}$ for HSC-3 cells and $0.8 \mu \mathrm{M}$ for HSC-4 cells) for each indicated time points $(0,3,6,12$ and $24 \mathrm{hr})$. As shown in Figure 1, the viability of HSC-3 and HSC-4 cells was notably decreased in a concentration- and time-dependent manner. These results indicate that WA can decrease cell viability in human oral cancer cells.

\subsection{WA Increased Apoptosis in HSC-3 and HSC-4 Cells}

To determine whether the growth inhibitory effect of WA was associated with apoptosis, we performed using DAPI staining. As presented in Figure 2, the exposure of cells to WA exhibited a noticeable increase in the distinct features of apoptotic cells such as chromatin condensation and nuclear fragmentation. These results suggest that growth inhibitory effect of WA may be associated with induction of apoptosis.

\subsection{WA-Induced Apoptosis Is Associated with Activation of Caspase 3 in HSC-3 and HSC-4 Cells}

Next, we carried out western blot analysis using antibody against cleaved PARP and caspase 3. The results showed that the augmentation of cleaved PARP and caspase 3 by WA was in a concentration-dependent in HSC-3 and HSC-4 cells (Figure 3(a)). Also, the results from western blot analysis showed that exposure of cells to WA caused a markedly induction of cleaved PARP in a time-dependent manner (Figure 3(b)). To identify the involvement of caspase 3 activation in WA-mediated apoptotic cell death, we used a pancaspase inhibitor, Z-VAD and the apoptosis induced by WA was modestly abolished by Z-VAD (Figure 3(c)). These results suggest that WA has caspase-dependent apoptotic activity in HSC-3 and HSC-4 cells.

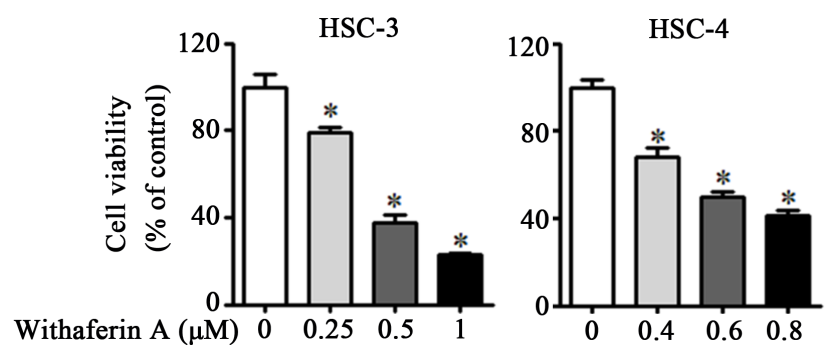

(a)

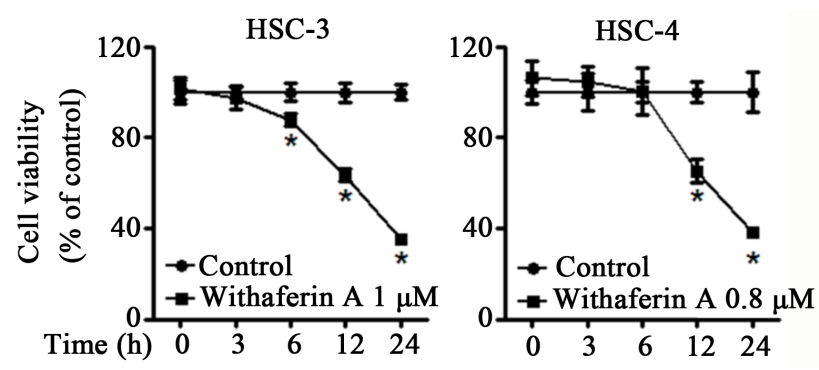

(b)

Figure 1. Withaferin A inhibits cell viability in human oral cancer cells. HSC-3 and HSC-4 cells were treated with DMSO or multiple concentrations of WA for $24 \mathrm{hr}$. A, The effect of WA on cell viability was examined using Trypan blue exclusion assay. $\mathrm{B}$, Each cell lines were harvested at different time points $(0,3,6,12$ and $24 \mathrm{hr})$. The graphs were expressed the mean \pm S.D. of triplicate experiments and significance $(p<$ 0.05 ) compared with the DMSO-treated group was indicated $\left(^{*}\right)$. 


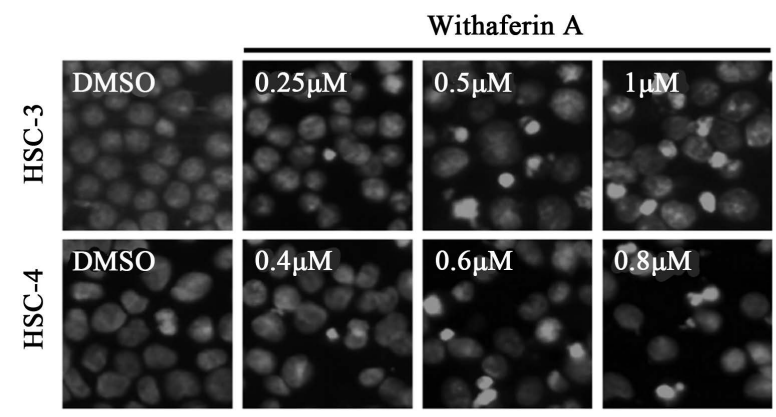

(a)

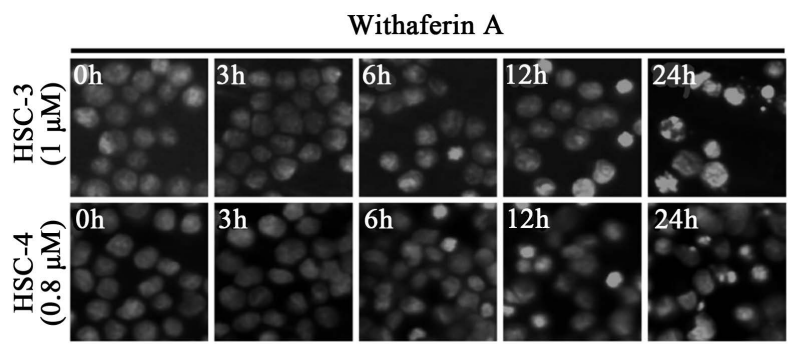

(b)

Figure 2. WA increases nuclear fragmentation and condensation in human oral cancer cells. HSC-3 and HSC-4 cells were treated with DMSO or various concentrations- and time-dependent of WA for $24 \mathrm{hr}$ and/or each time point. A and B, Nuclear condensation and DNA fragmentation were stained with DAPI solution as mentioned in Material and Methods (×400). DAPI-stained cells were observed by fluorescence microscopy.

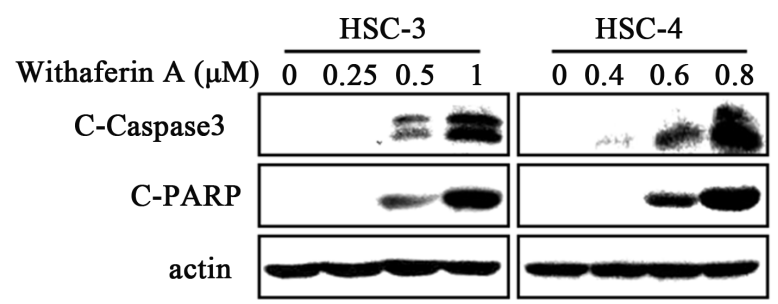

(a)

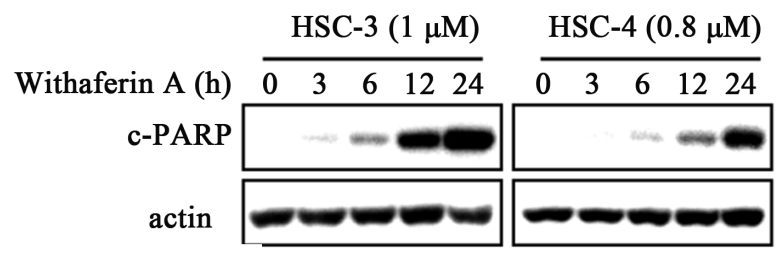

(b)

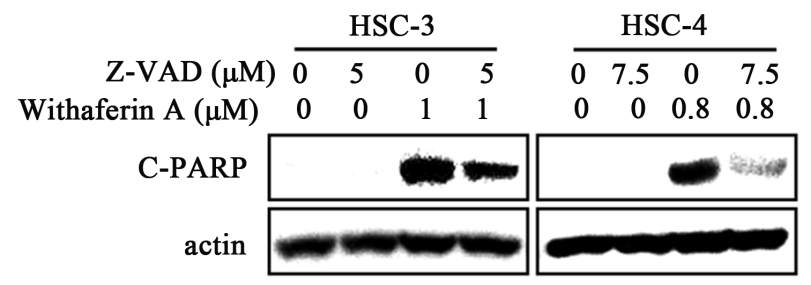

(c)

Figure 3. WA induces apoptosis in HSC-3 and HSC-4 cells. Total proteins were prepared for western blot with indicated antibodies. (a) HSC-3 and HSC-4 cells were treated with multiple concentration of WA; (b) Effect of WA was confirmed time dependently; (c) Pan-caspase inhibitor (Z-VAD) was used to evaluate the involvement of caspase 3 for WA-induced apoptosis, and actin was used as a loading control. 


\subsection{WA Induces Apoptosis through Regulation of Bim and Bax}

To clarify whether the apoptotic effect of WA is related to the regulation of Bcl-2 family proteins, we examined protein levels of Bim and Bax. As shown in Figure 4, WA increased Bim expression in HSC-3 cells and caused an increase in Bax in HSC-4 cells. These results suggest that WA-induced apoptosis may be associated with the regulation of several Bcl-2 family proteins in a cell line-specific manner.

\section{Discussion}

The natural synthetic or biological compounds have been used to treat cancers. Numerous studies have been demonstrated that natural compounds play critical roles in the induction of apoptosis in various cancers such as gastric, breast, lung and others cancers [24]-[26]. For example, a cacalol derived in Asian herbal plant has exerted anti-proliferative and apoptotic effect in breast cancer cells [27]. Eugenol has reported to induce apoptosis in human HT 29 colon cancer cells [28]. Previously, our group has demonstrated that several natural compounds such as Codonopis lanceolata and Tricholoma matsutake extracts exerted apoptotic activities through the augmentation of pro-apoptotic proteins, Bid and Bax levels in oral cancer [29]. Herein the present study, we showed that a natural compound, WA reduces cell viability and induced apoptosis in human oral cancer cells (Figures 1-3) indicating that WA may have anti-carcinogenic activities against oral cancer. WA has been reported as promising anti-cancer drug candidate due to its cytotoxic and apoptotic properties [30]. WA is known having a critical role in the inhibition of abnormal cell proliferation occurring in oral carcinogenesis [31]. Furthermore, anti-cancer effect of WA has demonstrated that it reduced cell viability and proliferation in adrenocortical carcinoma [32]. Thus, our results proved that WA has growth inhibitory and apoptotic effect in oral cancer cells.

The apoptotic pathway includes the extrinsic (cytoplasmic) and intrinsic (mitochondrial) pathway [33]. Permeabilization of the mitochondrial outer membrane is importantly associated with Bcl-2 family proteins that regulate the integrity of the mitochondria [34]. In particular, natural compound regulated the Bim expression of Bcl-2 member and induced apoptosis by cytochrome $\mathrm{C}$ release [35]. Antrodia camphorate extracts have been demonstrated that activation of caspase- $3,-8$, and -9 and the increase in the cytosolic level of cytochrome c were accompanied by increasing the expression levels of Bak, Bad and Bim in HeLa and C-33A cells [36]. Rhein also increased the expression of Bim and FOXO3a in MCF-7 and HepG2 cells during apoptosis [37]. Our group also has demonstrated that an analogue of curcumin, dibenzylideneacetone enhanced Bax expression resulting in apoptosis in oral cancer cells [38]. In the light of the potential effect by natural compounds on Bcl-2 family proteins, we assumed that WA could have pro-apoptotic properties through regulation of Bcl-2 family proteins. In

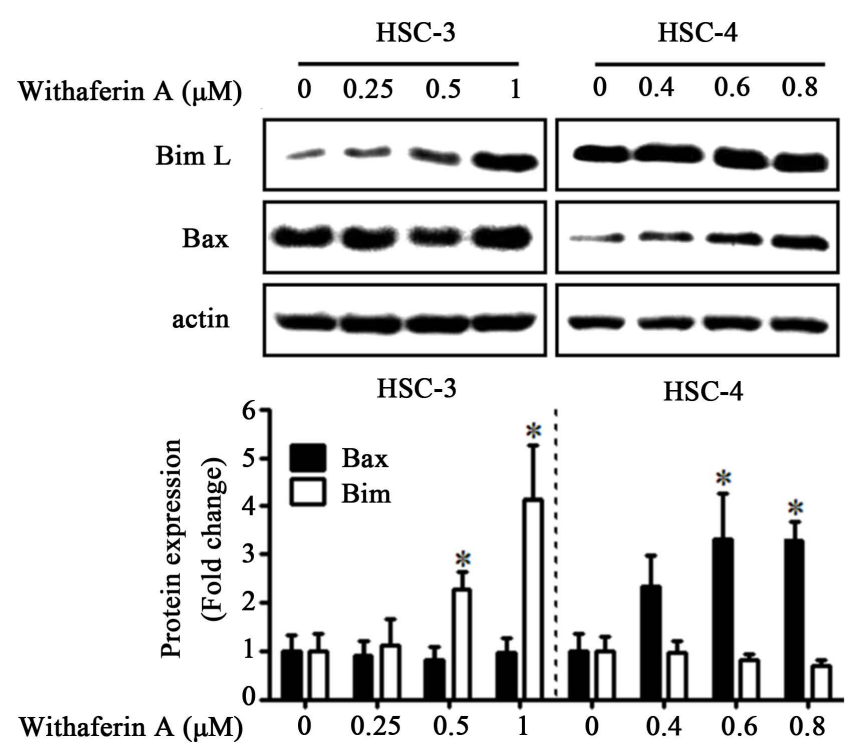

Figure 4. WA regulates Bim and Bax expression in HSC-3 and HSC-4 cells. HSC-3 and HSC -4 cells were treated with DMSO or various concentrations of WA for $24 \mathrm{hr}$. A and B, the cell lysates were analyzed by western blot using antibodies against Bim and Bax. 
practice, WA-induced apoptosis in human melanoma cells has reported that it correlated with mitochondrial pathway, which is regulated by Bcl-2 family protein, Bax and Bak and caspase-dependent pathway [13]. In this study, we also identified whether WA-induced apoptosis affects Bcl-2 family proteins and the results demonstrated that Bim and Bax were affected by WA in HSC-3 and HSC-4 cells, respectively (Figure 4). These results suggest that the up-regulation of Bim and Bax may be required for WA-induced apoptosis in oral cancer cells. Therefore, it would be valuable to further investigate continuously in future study.

\section{Conclusion}

In conclusion, our results show that WA reduces cell viability and upregulates the expression of Bim and Bax, leading to apoptosis in HSC-3 and HSC-4 oral cancer cells. Thus, these provide the basis that WA has an attractive chemotherapeutic drug candidate for therapy of oral cancer, although anti-tumorigenic effect of WA in vivo model is needed.

\section{References}

[1] Gibson, M.K., Li, Y., Murphy, B., Hussain, M.H., DeConti, R.C., Ensley, J., et al. (2005) Randomized Phase III Evaluation of Cisplatin plus Fluorouracil versus Cisplatin plus Paclitaxel in Advanced Head and Neck Cancer (E1395): An Intergroup Trial of the Eastern Cooperative Oncology Group. Journal of Clinical Oncology, 23, 3562-3567. http://dx.doi.org/10.1200/JCO.2005.01.057

[2] Zheng, G., Peng, C., Jia, X., Gu, Y., Zhang, Z., Deng, Y., et al. (2015) ZEB1 Transcriptionally Regulated Carbonic Anhydrase 9 Mediates the Chemoresistance of Tongue Cancer via Maintaining Intracellular pH. Molecular Cancer, 14, 84. http://dx.doi.org/10.1186/s12943-015-0357-6

[3] Casagrande, N., Celegato, M., Borghese, C., Mongiat, M., Colombatti, A. and Aldinucci, D. (2014) Preclinical Activity of the Liposomal Cisplatin Lipoplatin in Ovarian Cancer. Clinical Cancer Research, 20, 5496-5506. http://dx.doi.org/10.1158/1078-0432.CCR-14-0713

[4] Berruti, A., Terzolo, M., Sperone, P., Pia, A., Della Casa, S., Gross, D.J., et al. (2005) Etoposide, Doxorubicin and Cisplatin plus Mitotane in the Treatment of Advanced Adrenocortical Carcinoma: A Large Prospective Phase II Trial. Endocrine-Related Cancer, 12, 657-666. http://dx.doi.org/10.1677/erc.1.01025

[5] von Schwarzenberg, K. and Vollmar, A.M. (2013) Targeting Apoptosis Pathways by Natural Compounds in Cancer: Marine Compounds as Lead Structures and Chemical Tools for Cancer Therapy. Cancer Letters, 332, 295-303. http://dx.doi.org/10.1016/j.canlet.2010.07.004

[6] Choi, E.S., Kim, J.S., Kwon, K.H., Kim, H.S., Cho, N.P. and Cho, S.D. (2012) Methanol Extract of Sanguisorba officinalis L. with Cytotoxic Activity against PC3 Human Prostate Cancer Cells. Molecular Medicine Reports, 6, 670-674.

[7] Leeman-Neill, R.J., Wheeler, S.E., Singh, S.V., Thomas, S.M., Seethala, R.R., Neill, D.B., et al. (2009) Guggulsterone Enhances Head and Neck Cancer Therapies via Inhibition of Signal Transducer and Activator of Transcription-3. Carcinogenesis, 30, 1848-1856. http://dx.doi.org/10.1093/carcin/bgp211

[8] Sathya, S., Sudhagar, S., Vidhya Priya, M., Bharathi Raja, R., Muthusamy, V.S., Niranjali Devaraj, S., et al. (2010) 3beta-hydroxylup-20(29)-ene-27,28-dioic Acid Dimethyl Ester, a Novel Natural Product from Plumbago zeylanica Inhibits the Proliferation and Migration of MDA-MB-231 Cells. Chemico-Biological Interactions, 188, 412-420. http://dx.doi.org/10.1016/j.cbi.2010.07.019

[9] Woo, S.M., Min, K.J., Kim, S., Park, J.W., Kim, D.E., Kim, S.H., et al. (2014) Axl Is a Novel Target of Withaferin A in the Induction of Apoptosis and the Suppression of Invasion. Biochemical and Biophysical Research Communications, 451, 455-460. http://dx.doi.org/10.1016/j.bbrc.2014.08.018

[10] Rasool, M. and Varalakshmi, P. (2006) Immunomodulatory Role of Withania somnifera Root Powder on Experimental Induced Inflammation: An in Vivo and in Vitro Study. Vascular Pharmacology, 44, 406-410. http://dx.doi.org/10.1016/j.vph.2006.01.015

[11] Mohan, R., Hammers, H.J., Bargagna-Mohan, P., Zhan, X.H., Herbstritt, C.J., Ruiz, A., et al. (2004) Withaferin A Is a Potent Inhibitor of Angiogenesis. Angiogenesis, 7, 115-122. http://dx.doi.org/10.1007/s10456-004-1026-3

[12] Stan, S.D., Hahm, E.R., Warin, R. and Singh, S.V. (2008) Withaferin A Causes FOXO3a- and Bim-Dependent Apoptosis and Inhibits Growth of Human Breast Cancer Cells in Vivo. Cancer Research, 68, 7661-7669. http://dx.doi.org/10.1158/0008-5472.CAN-08-1510

[13] Mayola, E., Gallerne, C., Esposti, D.D., Martel, C., Pervaiz, S., Larue, L., et al. (2011) Withaferin A Induces Apoptosis in Human Melanoma Cells through Generation of Reactive Oxygen Species and Down-Regulation of Bcl-2. Apoptosis, 16, 1014-1027. http://dx.doi.org/10.1007/s10495-011-0625-x 
[14] Cory, S. and Adams, J.M. (2002) The Bcl2 Family: Regulators of the Cellular Life-or-Death Switch. Nature Reviews Cancer, 2, 647-656. http://dx.doi.org/10.1038/nrc883

[15] Taylor, R.C., Cullen, S.P. and Martin, S.J. (2008) Apoptosis: Controlled Demolition at the Cellular Level. Nature Reviews Molecular Cell Biology, 9, 231-241. http://dx.doi.org/10.1038/nrm2312

[16] Lomonosova, E. and Chinnadurai, G. (2008) BH3-Only Proteins in Apoptosis and Beyond: An Overview. Oncogene, 27, S2-S19. http://dx.doi.org/10.1038/onc.2009.39

[17] Kuwana, T., Bouchier-Hayes, L., Chipuk, J.E., Bonzon, C., Sullivan, B.A., Green, D.R., et al. (2005) BH3 Domains of BH3-Only Proteins Differentially Regulate Bax-Mediated Mitochondrial Membrane Permeabilization Both Directly and Indirectly. Molecular Cell, 17, 525-535. http://dx.doi.org/10.1016/j.molcel.2005.02.003

[18] Sehrawat, A. and Singh, S.V. (2015) Short-Form RON Overexpression Augments Benzyl Isothiocyanate-Induced Apoptosis in Human Breast Cancer Cells. Molecular Carcinogenesis. (In Press) http://dx.doi.org/10.1002/mc.22295

[19] Rah, B., Rasool, R.U., Nayak, D., Yousuf, S.K., Mukherjee, D., Kumar, L.D., et al. (2015) PAWR-Mediated Suppression of BCL2 Promotes Switching of 3-Azido Withaferin A (3-AWA)-Induced Autophagy to Apoptosis in Prostate Cancer Cells. Autophagy, 11, 314-331. http://dx.doi.org/10.1080/15548627.2015.1017182

[20] Li, X., Zhu, F., Jiang, J., Sun, C., Wang, X., Shen, M., et al. (2015) Synergistic Antitumor Activity of Withaferin A Combined with Oxaliplatin Triggers Reactive Oxygen Species-Mediated Inactivation of the PI3K/AKT Pathway in Human Pancreatic Cancer Cells. Cancer Letters, 357, 219-230. http://dx.doi.org/10.1016/j.canlet.2014.11.026

[21] Zhang, X., Samadi, A.K., Roby, K.F., Timmermann, B. and Cohen, M.S. (2012) Inhibition of Cell Growth and Induction of Apoptosis in Ovarian Carcinoma Cell Lines CaOV3 and SKOV3 by Natural Withanolide Withaferin A. Gynecologic Oncology, 124, 606-612. http://dx.doi.org/10.1016/j.ygyno.2011.11.044

[22] Cai, Y., Sheng, Z.Y., Chen, Y. and Bai, C. (2014) Effect of Withaferin A on A549 Cellular Proliferation and Apoptosis in Non-Small Cell Lung Cancer. Asian Pacific Journal of Cancer Prevention, 15, 1711-1714. http://dx.doi.org/10.7314/APJCP.2014.15.4.1711

[23] Samadi, A.K., Tong, X., Mukerji, R., Zhang, H., Timmermann, B.N. and Cohen, M.S. (2010) Withaferin A, a Cytotoxic Steroid from Vassobia breviflora, Induces Apoptosis in Human Head and Neck Squamous Cell Carcinoma. Journal of Natural Products, 73, 1476-1481. http://dx.doi.org/10.1021/np100112p

[24] Wu, J., Yi, W., Jin, L., Hu, D. and Song, B. (2012) Antiproliferative and Cell Apoptosis-Inducing Activities of Compounds from Buddleja Davidii in Mgc-803 Cells. Cell Division, 7, 20. http://dx.doi.org/10.1186/1747-1028-7-20

[25] Badmus, J.A., Ekpo, O.E., Hussein, A.A., Meyer, M. and Hiss, D.C. (2015) Antiproliferative and Apoptosis Induction Potential of the Methanolic Leaf Extract of Holarrhena floribunda (G. Don). Evidence-Based Complementary and Alternative Medicine, 2015, Article ID: 756482. http://dx.doi.org/10.1155/2015/756482

[26] Zhao, F., Hu, Y., Chong, C., Lu, M., Chen, L., Kan, W., et al. (2014) Ardisiphenol D, a Resorcinol Derivative Identified from Ardisia brevicaulis, Exerts Antitumor Effect through Inducing Apoptosis in Human Non-Small-Cell Lung Cancer A549 Cells. Pharmaceutical Biology, 52, 797-803. http://dx.doi.org/10.3109/13880209.2013.869231

[27] Tang, X., Shen, C., Cheema, S.A., Chen, L., Xiao, X., Zhang, C., et al. (2010) Levels and Distributions of Polycyclic Aromatic Hydrocarbons in Agricultural Soils in an Emerging E-Waste Recycling Town in Taizhou Area, China. Journal of Environmental Science and Health, Part A: Toxic/Hazardous Substances and Environmental Engineering, 45, 1076-1084. http://dx.doi.org/10.1080/10934529.2010.486336

[28] Jaganathan, S.K., Mazumdar, A., Mondhe, D. and Mandal, M. (2011) Apoptotic Effect of Eugenol in Human Colon Cancer Cell Lines. Cell Biology International, 35, 607-615. http://dx.doi.org/10.1042/CBI20100118

[29] Shin, J.A., Kim, J.S., Hong, I.S. and Cho, S.D. (2012) Bak Is a Key Molecule in Apoptosis Induced by Methanol Extracts of Codonopsis lanceolata and Tricholoma matsutake in HSC-2 Human Oral Cancer Cells. Oncology Letters, 4, 1379-1383.

[30] Patil, D., Gautam, M., Mishra, S., Karupothula, S., Gairola, S., Jadhav, S., et al. (2013) Determination of Withaferin A and Withanolide A in Mice Plasma Using High-Performance Liquid Chromatography-Tandem Mass Spectrometry: Application to Pharmacokinetics after Oral Administration of Withania somnifera Aqueous Extract. Journal of Pharmaceutical and Biomedical Analysis, 80, 203-212. http://dx.doi.org/10.1016/j.jpba.2013.03.001

[31] Panjamurthy, K., Manoharan, S., Nirmal, M.R. and Vellaichamy, L. (2009) Protective Role of Withaferin-A on Immunoexpression of p53 and Bcl-2 in 7,12-Dimethylbenz(a)Anthracene-Induced Experimental Oral Carcinogenesis. Investigational New Drugs, 27, 447-452. http://dx.doi.org/10.1007/s10637-008-9199-z

[32] Subramanian, C., Zhang, H., Gallagher, R., Hammer, G., Timmermann, B. and Cohen, M. (2014) Withanolides Are Potent Novel Targeted Therapeutic Agents against Adrenocortical Carcinomas. World Journal of Surgery, 38, 13431352. http://dx.doi.org/10.1007/s00268-014-2532-0

[33] Ghobrial, I.M., Witzig, T.E. and Adjei, A.A. (2005) Targeting Apoptosis Pathways in Cancer Therapy. CA: A Cancer Journal for Clinicians, 55, 178-194. http://dx.doi.org/10.3322/canjclin.55.3.178 
[34] Danial, N.N. and Korsmeyer, S.J. (2004) Cell Death: Critical Control Points. Cell, 116, 205-219. http://dx.doi.org/10.1016/S0092-8674(04)00046-7

[35] Zhao, L., He, F., Liu, H., Zhu, Y., Tian, W., Gao, P., et al. (2012) Natural Diterpenoid Compound Elevates Expression of Bim Protein, Which Interacts with Antiapoptotic Protein Bcl-2, Converting It to Proapoptotic Bax-Like Molecule. Journal of Biological Chemistry, 287, 1054-1065. http://dx.doi.org/10.1074/jbc.M111.264481

[36] Yang, P.Y., Hu, D.N. and Liu, F.S. (2013) Cytotoxic Effect and Induction of Apoptosis in Human Cervical Cancer Cells by Antrodia camphorata. The American Journal of Chinese Medicine, 41, 1169-1180. http://dx.doi.org/10.1142/S0192415X13500791

[37] Wang, J., Liu, S., Yin, Y., Li, M., Wang, B., Yang, L., et al. (2015) FOXO3-Mediated Up-Regulation of Bim Contributes to Rhein-Induced Cancer Cell Apoptosis. Apoptosis, 20, 399-409. http://dx.doi.org/10.1007/s10495-014-1071-3

[38] Yu, H.J., Shin, J.A., Nam, J.S., Kang, B.S. and Cho, S.D. (2013) Apoptotic Effect of Dibenzylideneacetone on Oral Cancer Cells via Modulation of Specificity Protein 1 and Bax. Oral Diseases, 19, 767-774.

http://dx.doi.org/10.1111/odi.12062 